\title{
Germinação de Sementes Aéreas e Subterrâneas de Commelina benghalensis ${ }^{1}$
}

\author{
Germination of Aerial and Underground Seeds of Commelina benghalensis
}

SANTOS, I.C. ${ }^{2}$, FERREIRA, F.A. ${ }^{3}$, MIRANDA, G.V. ${ }^{4}$ e SANTOS, L.D. T. ${ }^{5}$

\begin{abstract}
RESUMO - O conhecimento dos mecanismos de reprodução de uma espécie de planta daninha, principalmente em relação à dormência e germinação de suas sementes, é de grande importância na determinação do método e da época ideal de seu controle. Com o objetivo de avaliar a germinação de sementes aéreas e subterrâneas de Commelina benghalensis, plantas desta espécie foram cultivadas em vasos, em casa de vegetação, nas condições de Viçosa, Estado de Minas Gerais, Brasil. Semente subterrânea grande (SSG) e semente aérea pequena (SAP) apresentaram o maior e o menor peso $(8,81 \mathrm{e} 1,90 \mathrm{mg} / \mathrm{semente}$, respectivamente). Semente aérea grande (SAG) e semente subterrânea pequena (SSP) apresentaram pesos intermediários (3,65 e $3,51 \mathrm{mg} /$ semente, respectivamente), porém semelhantes entre si. A data de coleta das sementes aéreas influenciou seu peso, observando-se, nas condições do experimento e no intervalo considerado (setembro a dezembro), maior peso de semente na primeira coleta (24/9/1999). A germinação das sementes aéreas não foi influenciada pelo tempo de armazenamento. Sementes aéreas pequenas germinaram melhor a $20-35{ }^{\circ} \mathrm{C}$, e as grandes, a $25^{\circ} \mathrm{C}$. A germinação de sementes aéreas recém-colhidas variou de $7,50 \%$ em SAP a $21,67 \%$ em SAG/E (semente aérea grande com envoltório). O armazenamento por quatro meses aumentou a porcentagem de germinação de SAG e não alterou a de SAG/E e SAP. Sementes subterrâneas pequenas e grandes armazenadas por três meses apresentaram 32,5 e $92,5 \%$ de germinação, respectivamente. O aumento do tempo de armazenamento de três para seis meses diminuiu a porcentagem de germinação de SSG e SSP. O calor seco aumentou a porcentagem de germinação de SAG/E e SSP, não alterou a de SAG e SAP e diminuiu a de SSG. O grau de dormência diferiu muito entre os quatro tipos de sementes. A produção de sementes polimórficas com grandes diferenças no grau de dormência permite que C. benghalensis germine e se estabeleça nos mais diversificados ambientes e épocas do ano, o que dificulta o manejo desta espécie daninha.
\end{abstract}

Palavras-chave: trapoeraba, COMBE, sementes polimórficas, planta daninha, peso de semente.

\begin{abstract}
Understanding the reproductive mechanisms of a weed species, mainly concerning to its seeds' dormancy and germination is of great importance for determining the method and right time for its control. To evaluate the germination of aerial and underground seeds of Commelina benghalensis. plants were grown in pots under greenhouse conditions in Viçosa, Minas Gerais, Brazil. The large underground seed (SSG) and the small aerial seed (SAP) had the largest and the smallest seed weight of 8.81 and $1.90 \mathrm{mg} / \mathrm{seed}$, respectively. Large aerial seed (SAG) and small underground seed (SSP) had similar intermediate weights (3.65 and $3.51 \mathrm{mg} / \mathrm{seed}$, respectively). The aerial seed harvest date influenced their weight, with a production of heavier seeds in the first harvest (September, 24 1999) being observed during the experimental period and interval studied (September to December). Aerial seed germination was not influenced by storage time. SAP showed better germination percent at $20-35{ }^{\circ} \mathrm{C}$ and SAG at $25 \stackrel{\circ}{\circ}$. Germination of freshly harvested aerial seeds varied from $7.50 \%$ for SAP to $21.67 \%$ for SAG/E (large aerial seed with covering). Four-month storage increased SAG germination percent without altering it in SAG/E and SAP. Small and large underground seeds stored during three
\end{abstract}

Recebido para publicação em 12/2/2001 e na forma revisada em 2/7/2001.

2 Pesquisadora, Empresa de Pesquisa Agropecuária de Minas Gerais - Centro Tecnológico da Zona da Mata, Vila Gianetti, casa 46, 36571-000 Viçosa-MG; ${ }^{3}$ Professor Titular, Universidade Federal de Viçosa-UFV; ${ }^{4}$ Professor Adjunto, Universidade Federal de Viçosa-UFV; ${ }^{5}$ Estagiário, graduando do curso de Agronomia - UFV, 36571-000 Viçosa-MG.

Planta Daninha, Viçosa-MG, v.19, n.2, p.163-170, 2001 
months showed 32.5 and $92.5 \%$ of germination, respectively. Increasing storage time from three to six months decreased SSG and SSP germination percent. Germination percent was increased by dry heat in SAG/E and SSP, had no alteration in SAG and SAP, and decreased in SSG. The degree of dormancy differed among the four seed types. The production of polymorphic seeds showing great differences in dormancy degree allows $\mathbf{C}$. benghalensis to germinate and establish in the most diversified environments and seasons of the year, making difficult the management of this weed species.

Key words: dayflower, COMBE, dormancy, polymorphic seeds, weed, seed weight.

\section{INTRODUÇÃO}

Um dos aspectos da biologia de Commelina benghalensis, que a coloca entre as piores plantas daninhas do mundo, é sua eficiente capacidade de estabelecer e perpetuar-se em diferentes ambientes (Holm et al., 1977; Budd et al., 1979; Wilson, 1981). Além de se reproduzir vegetativamente por meio de rizomas e da emissão de raízes e brotos nos nós de pedaços do caule, $C$. benghalensis produz dois tipos de sementes: aéreas, oriundas de flores alogâmicas, e subterrâneas, oriundas de flores cleistogâmicas. Tanto as sementes aéreas quanto as subterrâneas são de dois tamanhos, motivo pelo qual são comumente denominadas: sementes aéreas grandes - SAG, sementes aéreas pequenas - SAP, sementes subterrâneas grandes - SSG e sementes subterrâneas pequenas - SSP (Maheshwari \& Maheshwari, 1955; Walker \& Evenson, 1985a; Rodrigues, 1992; Gonzalez \& Haddad, 1995). Cada um desses tipos de semente germina melhor em uma determinada profundidade, luminosidade e temperatura, o que possibilita a esta espécie vários fluxos de germinação durante o ano.

O peso dos quatro tipos de sementes está intimamente relacionado com o seu vigor. Segundo Kissmann \& Groth (1992), sementes subterrâneas grandes são capazes de germinar e emergir de uma profundidade de $12 \mathrm{~cm}$, enquanto as sementes aéreas não germinam em profundidade maior que $2 \mathrm{~cm}$. Com base na matéria seca e na área foliar, Kim (1998) concluiu que plantas oriundas de SSG emergiram e cresceram mais rápido e mais vigorosas que as oriundas dos outros três tipos de sementes, durante as quatro primeiras semanas. Walker \& Evenson (1985b) identificaram como profundidade ótima para a emergência dos quatro tipos de sementes a faixa de 0 a $50 \mathrm{~mm}$; no entanto, obtiveram correlação positiva entre profundidade de emergência e peso da semente.

Os quatro tipos de sementes produzidos por C. benghalensis exibem significativa diferença no grau de dormência, variando de baixíssimo em SSG a muito alto em SAP; SAG e SSP exibem alto grau de dormência (Maheshwari \& Maheshwari, 1955; Budd et al., 1979; Walker \& Evenson, 1985b). Devido ao fato de a dormência dessas sementes ser totalmente superada pelo rompimento do tegumento (Budd et al., 1979; Walker \& Evenson, 1985b; Gonzalez \& Haddad, 1995), acredita-se que as sementes sejam completamente viáveis e que a dormência seja causada, provavelmente, pelo impedimento à entrada de água e, ou, oxigênio causado pelo tegumento. Vários são os métodos já empregados para a quebra da dormência das sementes de $C$. benghalensis. Embora, em geral, os melhores resultados de quebra de dormência para os quatro tipos de sementes sejam os obtidos com o corte do tegumento com bisturi, Walker \& Evenson (1985b) advertem que o processo é trabalhoso e consome muito tempo; eles observaram que a exposição ao calor seco foi mais simples e rápida e também aumentou a germinação, que foi de $35 \%$ (testemunha) para $97 \%$ quando as SAG foram expostas a $75{ }^{\circ} \mathrm{C}$ por 24 horas.

Com relação ao efeito da luz, Walker \& Evenson (1985b) obtiveram germinação tanto na luz quanto no escuro, mas observaram que a germinação das sementes expostas à luz foi maior; além disso, as sementes subterrâneas responderam mais à luz que as sementes aéreas. Gonzalez \& Haddad (1995) obtiveram maior porcentagem de germinação de SAP e sementes subterrâneas sob luz constante, enquanto a SAG o fez sob escuro, fato que contradiz a afirmação de Klein \& Felippe (1992), citados por Gonzalez \& Haddad (1995), de que 
as sementes aéreas de $C$. benghalensis são fotoblásticas positivas.

Walker \& Evenson (1985b) estudaram o efeito da temperatura constante na germinação, num gradiente de 15 a $36{ }^{\circ} \mathrm{C}$, e verificaram que ocorreu germinação de SAG e SSG de 15 até $36{ }^{\circ} \mathrm{C}$ e de SAP e SSP de 18 até $36^{\circ} \mathrm{C}$. A $24^{\circ} \mathrm{C}$, SAG, SSG e SAP apresentaram germinação máxima (93, 99 e 99\%, respectivamente), enquanto as SSP o fizeram a $28{ }^{\circ} \mathrm{C}(95 \%)$, o que foi confirmado por Gonzalez \& Haddad (1995), ao constatarem que os percentuais de germinação a $25{ }^{\circ} \mathrm{C}$ foram numericamente maiores que a $30^{\circ} \mathrm{C}$.

As diferenças em dormência e germinação em resposta à luz e temperatura, bem como em emergência em relação à profundidade, estão intimamente associadas ao polimorfismo das sementes e têm significado ecológico para C. benghalensis. Os diferentes tipos de sementes podem germinar e emergir sob diferentes condições, possibilitando a essa planta adaptar-se a novos ambientes (Walker \& Evenson, 1985b). Wilson (1981) considerou essa adaptabilidade como o principal fator determinante do sucesso e da disseminação de $C$. benghalensis como planta daninha.

O objetivo deste trabalho foi estudar a germinação de sementes aéreas e subterrâneas provenientes de plantas de $C$. benghalensis cultivadas em casa de vegetação.

\section{MATERIAL E MÉTODOS}

Sementes de Commelina benghalensis, adquiridas da Shokucho do Brasil Agrícola Ltda. (Fazenda Experimental - Engenheiro Coelho-SP), foram semeadas, em 6/3/99, em 20 vasos, em casa de vegetação. As espatas aéreas foram coletadas quando estavam totalmente secas e então "abertas" para liberação das sementes, que foram separadas manualmente por tamanho e acondicionadas em envelopes de papel pardo, que foram colocados em gavetas, no laboratório, à temperatura ambiente. As coletas foram realizadas à medida que as espatas ficavam secas, até dezembro de 1999, quando a parte aérea foi eliminada e a irrigação suspensa. Em janeiro de 2000, estando o substrato seco, os frutos subterrâneos foram separados.
Trabalhou-se com os quatro tipos de sementes de $C$. benghalensis referidos na literatura: sementes aéreas grandes (SAG), sementes aéreas pequenas (SAP), sementes subterrâneas grandes (SSG) e sementes subterrâneas pequenas (SSP). Observou-se, porém, que, ao se abrirem as espatas para liberação das sementes, a semente aérea grande permanecia envolvida por tecido do fruto e que somente com algum esforço é que se podia removê-lo, motivo pelo qual ela foi denominada "semente aérea grande com envoltório - SAG/E” e incluída como mais um tipo de semente em um dos testes de germinação, por ser desconhecido se, ao cair no solo assim protegida, esta semente seria favorecida ou prejudicada durante a germinação.

O estudo do peso de sementes (ensaio 1) foi realizado com SAG e SAP colhidas em 4/12/99 e SSG e SSP colhidas em janeiro de 2000, pesando-se 10 amostras (repetições) de 10 sementes dos quatro tipos (tratamentos), para cálculo do peso médio por semente. Utilizou-se o delineamento inteiramente casualizado.

O efeito da época de desenvolvimento e de coleta no peso de SAG e SAP (ensaio 2) foi estudado através da pesagem de dez amostras de dez sementes, logo após a coleta, nas seguintes datas: 24/9,7/10, 27/10, 8/11 e 4/12 de 1999. Utilizou-se o delineamento de parcelas subdivididas, sendo os tamanhos de sementes as parcelas, e as datas de coleta, as subparcelas. Estimou-se a equação de regressão para peso de sementes em função da data de coleta, considerando $24 / 9$ o dia zero e 4/12 o $71^{\circ}$ dia de coleta.

As Regras para Análise de Sementes (Brasil, 1992) não apresentam informações para a condução do teste de germinação de espécies do gênero Commelina L., motivo pelo qual foram utilizadas condições semelhantes às citadas em trabalhos de outros autores. $\mathrm{O}$ número de repetições e o número de sementes utilizadas em cada repetição se deram em função do número de sementes disponíveis, coincidindo com a metodologia adotada por Kim (1998) e Gonzalez \& Haddad (1995).

No ensaio 3, sementes aéreas de C. benghalensis foram coletadas em seis datas durante um ano. Após cada coleta, as sementes foram separadas manualmente por tamanho e 
acondicionadas em sacos de papel pardo, que foram guardados em gavetas, à temperatura ambiente, até que a última coleta fosse feita, quando então se realizou um único teste de germinação. Portanto, a cada época de coleta está associado um tempo de armazenamento (em dias), conforme indicado a seguir: 15/5/99 (414), 24/9/99 (282), 27/10/99 (249), 17/11/99 (228), 15/12/99 (200) e 28/5/2000 (35). O efeito do tempo de armazenamento na germinação de sementes aéreas foi estudado a $25{ }^{\circ} \mathrm{C}$ constantes e com alternância de luz e escuro (10 e 14 horas por dia, respectivamente). Os tamanhos de sementes constituíram as parcelas, e os tempos de armazenamento, as subparcelas desse ensaio no delineamento inteiramente casualizado, com quatro repetições de dez sementes.

No ensaio 4, sementes aéreas de duas idades (recém-colhidas ou armazenadas por quatro meses) foram submetidas a três condições: a) germinador a $20-35^{\circ} \mathrm{C}$, sendo 10 horas de luz a $35{ }^{\circ} \mathrm{C}$ e 14 horas de escuro a $20{ }^{\circ} \mathrm{C}$ por dia; b) germinador a $25{ }^{\circ} \mathrm{C}$ constantes e 10 horas de luz por dia; e c) germinador a $25{ }^{\circ} \mathrm{C}$ constantes e 10 horas de luz por dia, após choque térmico seco (CTS). A exposição ao calor seco foi realizada colocando-se as sementes em placas de Petri forradas com papel germitest, que foram deixadas por 24 horas em estufa com ventilação forçada de ar e temperatura ajustada em $75^{\circ} \mathrm{C}$, conforme descrição de Walker \& Evenson (1985b). Na análise de variância foram aplicados na parcela os tratamentos principais, combinação de três tipos de sementes (sendo aqui incluída a semente aérea grande com envoltório - SAG/E) e três condições do teste de germinação, e na subparcela a idade da semente. Foram feitas quatro repetições.

No ensaio 5, antes do teste de germinação, conduzido a $25{ }^{\circ} \mathrm{C}$ constantes e com 10 horas de luz por dia, sementes subterrâneas (SSG e SSP) foram submetidas aos tratamentos: armazenamento por três meses; armazenamento por três meses + CTS (descrito anteriormente); e armazenamento por seis meses. Esse fatorial foi conduzido no delineamento inteiramente casualizado, com quatro repetições.

Em todos os testes de germinação, conduzidos em germinador tipo Mangelsdorf, as sementes foram higienizadas com hipoclorito de sódio a $2,5 \%$ e semeadas em caixas do tipo gerbox forradas com papel germitest umedecido com quantidade de água destilada equivalente a 2,5 vezes o peso do papel. As avaliações foram realizadas de dois em dois dias, a partir do início da germinação, por meio de contagem e retirada das plântulas normais, das plântulas anormais deformadas e deterioradas e das sementes mortas, até 23 dias após a semeadura, quando foram contadas as sementes dormentes (Brasil, 1992). O índice de velocidade de germinação (IVG) foi calculado por meio da seguinte fórmula, citada por Maguire (1962): $I V G=G_{1} / N_{1}+G_{2} / N_{2} \ldots \ldots . .+G_{n} / N_{n}$, em que $\mathrm{G}_{1}, \mathrm{G}_{2}, \ldots \ldots \mathrm{G}_{\mathrm{n}}=$ número de plântulas normais na primeira, na segunda e na enésima contagem; e $\mathrm{N}_{1}, \mathrm{~N}_{2}, \ldots . . \mathrm{N}_{\mathrm{n}}$ = número de dias da semeadura na primeira, na segunda e na enésima contagem.

Para análise estatística dos dados, foi utilizado o programa SAEG, transformando os dados, quando necessário, antes de submetêlos à análise de variância. As médias das variáveis foram comparadas pelo teste de Tukey.

\section{RESULTADOS E DISCUSSÃO}

A análise de variância dos dados do ensaio 1 revelou efeito significativo $(\mathrm{P}<0,01)$ dos tipos de sementes de $C$. benghalensis sobre o seu peso (Tabela 1), o que corrobora os resultados de trabalhos semelhantes, nos quais SSG e SAP apresentaram o maior e o menor peso de semente, respectivamente (Walker \& Evenson, 1985a; Rodrigues, 1992; Gonzalez \& Haddad, 1995; Kim, 1998). Observa-se, porém, comparando os trabalhos citados, que os quatro tipos de sementes apresentam grande variação no peso (em mg): 3,97 a 6,1 para SAG; 2,18 a 3,8 para SAP; 8,3 a 15,3 para SSG; e 4,4 a 6,95 para SSP. Excetuando SSG, os resultados apresentados na Tabela 1 estão abaixo da faixa de variação encontrada na literatura consultada, o que se deve, provavelmente, a diferenças entre os ambientes onde as plantas cresceram e produziram sementes.

No ensaio 2, a análise de variância confirmou o efeito do tipo de semente e revelou efeito da época de coleta $(\mathrm{P}<0,01)$, mas não da interação sobre o peso das sementes. Portanto, as condições ambientais anteriores à coleta influenciaram o peso tanto da SAG quanto da 
SAP, ajustando-se o modelo quadratico para esse efeito (Figura 1), mas não alteraram a relação de tamanho entre elas. Dentro do intervalo utilizado neste experimento $(24 / 9$ a $4 / 12$ ), estima-se que sementes de maior peso sejam produzidas no início da primavera; a partir daí, as sementes apresentariam peso decrescente. Além do efeito da temperatura e de fotoperiodo, deve-se considerar na análise desses resultados o esgotamento do substrato, pois as plantas foram cultivadas em vasos.

Tabela 1 - Peso médio dos diferentes tipos de sementes de C. benghalensis - dados originais

\begin{tabular}{|l|c|}
\hline \multicolumn{1}{|c|}{ Tipos de Sementes } & $\begin{array}{c}\text { Peso médio } \\
(\mathrm{mg} / \text { semente })\end{array}$ \\
\hline SAG (Semente aérea grande) & $3,65 \mathrm{~b}$ \\
\hline SAP (Semente aérea pequena) & $1,90 \mathrm{c}$ \\
\hline SSG (Semente subterrânea grande) & $8,81 \mathrm{a}$ \\
\hline SSP (Semente subterrânea pequena) & $3,51 \mathrm{~b}$ \\
\hline
\end{tabular}

- Médias seguidas da mesma letra não diferem entre si a 5\% de probabilidade, pelo teste de Tukey. A análise estatística foi realizada com os dados transformados para $\sqrt{x+1}$.

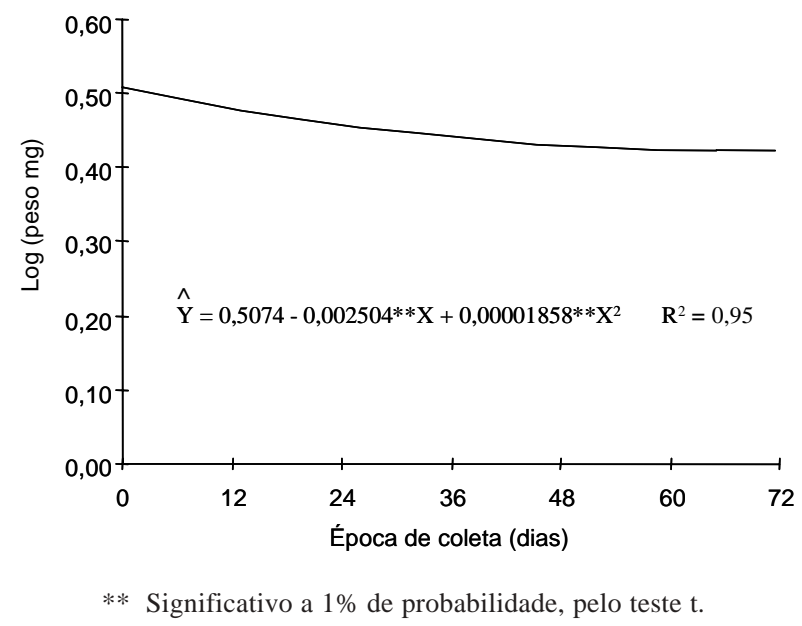

Figura 1 - Equação estimada para o peso de sementes aéreas de $C$. benghalensis, em função da época de coleta (1: 24/9, 2: 7/10, 3: 27/10, 4: 8/11 e 5: 4/12/99).

A análise de variância dos dados de germinação de sementes aéreas (ensaio 3) revelou efeito $(\mathrm{P}<0,01)$ do tipo de semente sobre a porcentagem de sementes germinadas e dormentes e sobre o IVG, mas não houve efeito do tempo de armazenamento sobre as variáveis avaliadas, embora haja diferença de mais de um ano entre a primeira e a última coleta. SAG apresentou maior porcentagem de sementes germinadas e maior IVG em relação a SAP (Tabela 2), valores esses muito inferiores aos obtidos por Rodrigues (1992) para SAG e SAP (35,3 e $15,9 \%$ de sementes germinadas, respectivamente) colhidas em Paranavaí-SP, porém próximos aos obtidos pelo mesmo autor para SAG $(8,1 \%)$ e SAP $(6,6 \%)$ colhidas em Jaboticabal-SP. Martin \& Carnahan (1983) sugerem que as diferenças na germinação entre os tipos de sementes em resposta à luz e temperatura podem ser atribuídas às diferentes condições ambientais sob as quais sementes aéreas e subterrâneas cresceram e anadureceram. Variação no percentual de germinação de Chromolaena odorata em função do local de coleta das sementes foi registrada por Erasmus \& Van Staden (1987), citados por Rodrigues (1992).

Tabela 2 - Efeito do tamanho da semente aérea de C. benghalensis sobre as porcentagens de sementes germinadas, dormentes e mortas e sobre o índice de velocidade de germinação (IVG) - dados originais

\begin{tabular}{|l|c|c|}
\hline Características avaliadas & $\begin{array}{c}\text { Semente aérea } \\
\text { grande (SAG) }\end{array}$ & $\begin{array}{c}\text { Semente aérea } \\
\text { pequena (SAP) }\end{array}$ \\
\hline Sementes germinadas (\%) & $10,83 \mathrm{~A}$ & $1,67 \mathrm{~B}$ \\
\hline Sementes dormentes (\%) & $85,42 \mathrm{~B}$ & $96,25 \mathrm{~A}$ \\
\hline Sementes mortas (\%) & $3,75 \mathrm{~A}$ & $2,08 \mathrm{~A}$ \\
\hline IVG & $0,14 \mathrm{~A}$ & $0,01 \mathrm{~B}$ \\
\hline
\end{tabular}

- Para cada característica avaliada, médias seguidas da mesma letra, na linha, não diferem entre si a $5 \%$ de probabilidade, pelo teste de Tukey. A análise estatística foi realizada com os dados de porcentagem de sementes germinadas e dormentes transformados para arco seno [raiz (controle/100)] e do IVG transformados para $\log (x+0,01)$.

No ensaio 4, nenhuma das fontes de variação teve efeito sobre a porcentagem de sementes mortas $(\mathrm{P}>0,05)$. Entretanto, sobre porcentagem de sementes germinadas e IVG, o efeito das três fontes principais de variação (tipo de semente - TS, condição do teste de germinação - CT e idade da semente - IS) e das interações TS x CT e IS x TS foi significativo 
$(\mathrm{P}<0,01)$. A porcentagem de sementes dormentes foi influenciada pelo tipo de semente, pela condição do teste e pela interação IS $\mathrm{x}$ TS, com $\mathrm{P}<0,01$, e pela idade da semente e TS $\mathrm{x}$ CT, com $\mathrm{P}<0,05$. A interação IS $\times \mathrm{CT}$ afetou apenas o IVG $(\mathrm{P}<0,01)$. Na Tabela 3 , observa-se que somente SAG/E apresentou diferença na germinação em função das condições do teste, sendo maior a $25{ }^{\circ} \mathrm{C}$ após CTS, o que corrobora os resultados apresentados por Walker \& Evenson (1985b), que obtiveram aumento na germinação de 35 para 97\% na SAG, e diverge quanto a SAP, na qual eles obtiveram aumento de 33 para 52\% de germinação após 24 horas a $75{ }^{\circ} \mathrm{C}$ (calor seco). A temperatura de $25{ }^{\circ} \mathrm{C}$ e o choque térmico seco aumentaram o IVG de SAG e SAG/E em relação a 20-35 ${ }^{\circ} \mathrm{C}$. Ainda na Tabela 3 , observa-se que, a $25^{\circ} \mathrm{C}$, sementes grandes apresentaram maior germinação que SAP e que estas apresentaram tendência de melhor germinação a 20/35 드, o que corrobora os resultados de Walker \& Evenson (1985b), os quais observaram melhor germinação de SAG a $24{ }^{\circ} \mathrm{C}$ e de SAP a $28{ }^{\circ} \mathrm{C}$.
Observa-se na Tabela 4 que, tanto para sementes recém-colhidas quanto para as armazenadas por quatro meses, SAG e SAG/E apresentaram maiores porcentagens de germinação que SAP. Somente as SAG e SAG/E tiveram sua germinação e, conseqüentemente, o IVG aumentados pelo efeito do armazenamento. $\mathrm{O}$ fato de o armazenamento ter aumentado a germinação da SAG e não da SAG/E sugere que o envoltório atuou evitando a quebra de dormência, mas o IVG das SAG/E aumentou após o armazenamento. Ou seja, durante este período, a SAG/E passou por algum processo físico e, ou, fisiológico que a fez germinar mais rápido em relação às recém-colhidas. Levantase como hipótese a possibilidade de o envoltório aumentar a molhabilidade da semente, ou a presença de promotores da germinação no envoltório. Na Tabela 5, observa-se que, no caso de sementes aéreas recém-colhidas, as condições do teste de germinação não influenciaram o IVG, mas, para as sementes armazenadas por quatro meses, o IVG foi maior a $25{ }^{\circ} \mathrm{C}$, sem e com CTS.

Tabela 3 - Efeito do tamanho da semente aérea de C. benghalensis e da condição de condução do teste de germinação sobre as porcentagens de sementes germinadas e dormentes e sobre o índice de velocidade de germinação (IVG) - dados originais

\begin{tabular}{|c|c|c|c|c|c|c|c|c|c|}
\hline \multirow[b]{2}{*}{ Tipo de semente } & \multicolumn{3}{|c|}{ Sementes Germinadas (\%) } & \multicolumn{3}{|c|}{ Sementes Dormentes $(\%)$} & \multicolumn{3}{|c|}{ IVG } \\
\hline & $20 / 35^{\circ} \mathrm{C}$ & $25^{\circ} \mathrm{C}$ & $\begin{array}{c}25^{\circ} \mathrm{C} \text { após } \\
\mathrm{CTS}^{1 /}\end{array}$ & $20 / 35^{\circ} \mathrm{C}$ & $25^{\circ} \mathrm{C}$ & $\begin{array}{c}25^{\circ} \mathrm{C} \text { após } \\
\mathrm{CTS}^{1 /}\end{array}$ & $20-35^{\circ} \mathrm{C}$ & $25^{\circ} \mathrm{C}$ & $\begin{array}{c}25^{\circ} \mathrm{C} \text { após } \\
\mathrm{CTS}^{1 /}\end{array}$ \\
\hline Semente aérea grande (SAG) & $20,00 \mathrm{Aa}$ & $27,50 \mathrm{Aa}$ & $36,25 \mathrm{Aa}$ & $73,75 \mathrm{Aa}$ & $71,25 \mathrm{Ab}$ & $56,25 \mathrm{Ab}$ & $0,1657 \mathrm{Ba}$ & $0,3970 \mathrm{Aa}$ & $0,3600 \mathrm{ABb}$ \\
\hline $\begin{array}{l}\text { Semente aérea grande com } \\
\text { envoltório }(\mathrm{SAG} / \mathrm{E})\end{array}$ & $7,50 \mathrm{Ba}$ & $22,08 \mathrm{Bab}$ & $50,41 \mathrm{Aa}$ & $85,00 \mathrm{Aa}$ & $69,58 \mathrm{ABb}$ & $47,92 \mathrm{Bb}$ & $0,0596 \mathrm{Ba}$ & $0,2888 \mathrm{Ba}$ & $0,6422 \mathrm{Aa}$ \\
\hline Semente aérea pequena (SAP) & $10,00 \mathrm{Aa}$ & $5,00 \mathrm{Ab}$ & $3,75 \mathrm{Ab}$ & $81,25 \mathrm{Aa}$ & $95,00 \mathrm{Aa}$ & $86,25 \mathrm{Aa}$ & $0,1005 \mathrm{Aa}$ & $0,0557 \mathrm{Ab}$ & $0,0295 \mathrm{Ac}$ \\
\hline
\end{tabular}

- Para cada característica avaliada, médias seguidas da mesma letra maiúscula na linha e minúscula na coluna não diferem entre si a 5\% de probabilidade, pelo teste de Tukey. A análise estatística do IVG foi realizada com os dados transformados para raiz quadrada.

1/ CTS: choque térmico seco.

Tabela 4 - Efeito do tipo e da idade de sementes aéreas de C. benghalensis sobre as porcentagens de sementes germinadas, dormentes e mortas e sobre o índice de velocidade de germinação (IVG) - dados originais

\begin{tabular}{|c|c|c|c|c|c|c|c|c|}
\hline \multirow[b]{2}{*}{ Tipo de semente } & \multicolumn{2}{|c|}{ Sementes Germinadas } & \multicolumn{2}{|c|}{ Sementes Dormentes } & \multicolumn{2}{|c|}{ Sementes Mortas ${ }^{1 /}$} & \multicolumn{2}{|c|}{ IVG } \\
\hline & $\begin{array}{l}\text { Recém- } \\
\text { colhidas }\end{array}$ & $\begin{array}{c}\text { Armazenadas } \\
\text { por } 4 \text { meses }\end{array}$ & $\begin{array}{l}\text { Recém- } \\
\text { colhidas }\end{array}$ & $\begin{array}{l}\text { Armazenadas } \\
\text { por } 4 \text { meses }\end{array}$ & $\begin{array}{l}\text { Recém- } \\
\text { colhidas }\end{array}$ & $\begin{array}{l}\text { Armazenadas } \\
\text { por } 4 \text { meses }\end{array}$ & $\begin{array}{l}\text { Recém- } \\
\text { colhidas }\end{array}$ & $\begin{array}{c}\text { Armazenadas } \\
\text { por } 4 \text { meses }\end{array}$ \\
\hline Semente aérea grande (SAG) & $12,50 \mathrm{Bab}$ & $43,33 \mathrm{Aa}$ & $79,16 \mathrm{Aa}$ & $55,00 \mathrm{Bb}$ & 8,34 & 1,67 & $0,1824 \mathrm{Ba}$ & $0,4327 \mathrm{Aa}$ \\
\hline $\begin{array}{l}\text { Semente aérea grande com } \\
\text { envoltório (SAG/E) }\end{array}$ & $21,67 \mathrm{Aa}$ & $31,66 \mathrm{Aa}$ & $73,33 \mathrm{Aa}$ & $61,67 \mathrm{Ab}$ & 5,00 & 6,67 & $0,2425 \mathrm{Ba}$ & $0,4179 \mathrm{Aa}$ \\
\hline Semente aérea pequena (SAP) & $7,50 \mathrm{Ab}$ & $5,00 \mathrm{Ab}$ & $83,33 \mathrm{Aa}$ & $91,66 \mathrm{Aa}$ & 9,17 & 3,34 & $0,0906 \mathrm{Aa}$ & $0,0333 \mathrm{Ab}$ \\
\hline
\end{tabular}

- Para cada característica avaliada, médias seguidas da mesma letra maiúscula na linha e minúscula na coluna não diferem entre si a 5\% de probabilidade, pelo teste de Tukey. A análise estatística do IVG foi realizada com os dados transformados para raiz quadrada.

1/ Teste F não significativo a $5 \%$ de probabilidade. 
Tabela 5 - Efeito das condições do teste de germinação e da idade de sementes aéreas de $C$. benghalensis sobre o índice de velocidade de germinação - dados originais

\begin{tabular}{|c|c|c|}
\hline \multirow{2}{*}{$\begin{array}{c}\text { Condições do teste de } \\
\text { germinação }\end{array}$} & \multicolumn{2}{|c|}{ Idade da Semente } \\
\cline { 2 - 3 } & Recém-colhidas & $\begin{array}{c}\text { Armazenadas por } \\
4 \text { meses }\end{array}$ \\
\hline $20-35^{\circ} \mathrm{C}$ & $0,11 \mathrm{Aa}$ & $0,10 \mathrm{Ba}$ \\
\hline $25^{\circ} \mathrm{C}$ & $0,11 \mathrm{Ab}$ & $0,38 \mathrm{Aa}$ \\
\hline $\begin{array}{c}25^{\circ} \mathrm{C} \text { após choque } \\
\text { térmico seco }\end{array}$ & $0,28 \mathrm{Aa}$ & $0,40 \mathrm{Aa}$ \\
\hline
\end{tabular}

- Para cada idade da semente, médias seguidas da mesma letra maiúscula na linha e minúscula na coluna não diferem entre si a 5\% de probabilidade, pelo teste de Tukey. A análise estatística do IVG foi realizada com os dados transformados para raiz quadrada.

Informações sobre a temperatura ideal para a germinação de sementes de plantas daninhas podem ser usadas para predizer a temperatura do solo requerida para a emergência delas no campo (Blackshaw et al., 1981). Considerando as condições edafoclimáticas de Kingaroy, ao sudeste da Austrália, Walker \& Evenson (1985b) calcularam os períodos prováveis de maior infestação por $C$. benghalensis cruzando as informações sobre a melhor temperatura para a germinação dos quatro tipos de sementes e a temperatura do solo de Kingaroy a $2 \mathrm{~cm}$ de profundidade. Plântulas oriundas de sementes grandes, aéreas e subterrâneas, emergiriam de setembro a maio, e as oriundas de sementes pequenas, de outubro a abril, o que realmente acontece em condições naturais.
A análise de variância dos dados do ensaio 5 revelou efeito significativo $(\mathrm{P}<0,01)$ do tamanho da semente subterrânea, dos tratamentos que antecederam o teste de germinação e da interação entre eles sobre as variáveis (exceto da interação sobre sementes dormentes), motivo pelo qual se procedeu ao desdobramento da interação. Observa-se na Tabela 6 que, após três meses de armazenamento, SSG germinaram mais que SSP e que ambas diminuíram seu poder de germinação com o aumento do tempo de armazenamento de três para seis meses, sendo esse efeito mais pronunciado nas SSGs. O CTS exerceu efeito negativo sobre SSG, reduzindo a porcentagem de germinação de 92,5 para $52,5 \%$ e elevando a porcentagem de sementes mortas de 0 para $47,5 \%$. Esse comportamento se deve, provavelmente, ao fato de as SSG praticamente não apresentarem dormência, o que deve torná-las mais sensíveis ao CTS. Na SSP percebe-se tendência de aumento da germinação após CTS, provavelmente devido à quebra de dormência de parte das sementes.

Comparando os resultados apresentados na Tabela 4 para sementes aéreas armazenadas por quatro meses e os resultados apresentados na Tabela 6 para sementes subterrâneas armazenadas por três meses, percebe-se que, sob condições semelhantes, SSG germinou muito melhor que SAG $(92,5$ e $43,33 \%$, respectivamente), o mesmo ocorrendo em relação a SSP e SAP, com 32,5 e $5 \%$ de germinação, respectivamente.

Tabela 6 - Efeito dos tratamentos que antecederam o teste de germinação sobre as porcentagens de sementes germinadas, dormentes e mortas e sobre o índice de velocidade de germinação (IVG) de sementes subterrâneas grandes (SSG) e pequenas (SSP) de C. benghalensis - dados originais

\begin{tabular}{|l|c|c|c|c|c|c|c|c|}
\hline \multirow{2}{*}{ Tratamentos } & \multicolumn{2}{|c|}{ Sementes Germinadas } & \multicolumn{2}{|c|}{ Sementes Dormentes } & \multicolumn{2}{|c|}{ Sementes Mortas } & \multicolumn{2}{c|}{ IVG } \\
\cline { 2 - 10 } & SSG & SSP & SSG & SSP & SSG & SSP & SSG & SSP \\
\hline Três meses de armazenamento & $92,5 \mathrm{Aa}$ & $32,5 \mathrm{Bab}$ & $7,5 \mathrm{Bb}$ & $65,0 \mathrm{Aab}$ & $0,0 \mathrm{Ac}$ & $2,5 \mathrm{Aa}$ & $1,53 \mathrm{Aa}$ & $0,35 \mathrm{Bab}$ \\
\hline $\begin{array}{l}\text { Três meses de armazenamento } \\
\text { + choque térmico seco }\end{array}$ & $52,5 \mathrm{Ab}$ & $55,0 \mathrm{Aa}$ & $0,0 \mathrm{Bb}$ & $45,0 \mathrm{Ab}$ & $47,5 \mathrm{Aa}$ & $0,0 \mathrm{Ba}$ & $0,70 \mathrm{Ab}$ & $0,69 \mathrm{Aa}$ \\
\hline \begin{tabular}{l} 
Seis meses de armazenamento \\
\hline
\end{tabular} & $35,0 \mathrm{Ab}$ & $17,5 \mathrm{Ab}$ & $32,5 \mathrm{Ba}$ & $70,0 \mathrm{Aa}$ & $32,5 \mathrm{Ab}$ & $12,5 \mathrm{Ba}$ & $0,52 \mathrm{Ab}$ & $0,24 \mathrm{Ab}$ \\
\hline
\end{tabular}

- Para cada característica avaliada, médias seguidas da mesma letra maiúscula na coluna e minúscula na linha não diferem entre si a 5\% de probabilidade, pelo teste de Tukey. 
Nas condições metodológicas nas quais os ensaios foram conduzidos e seus respectivos resultados analisados, pode-se concluir, sobre as sementes de $C$. benghalensis que, tanto as sementes aéreas quanto as subterrâneas apresentaram peso de semente inferior à faixa de variação encontrada na literatura consultada. SSG e SAP apresentaram o maior e o menor peso de semente, respectivamente, enquanto SAG e SSP apresentaram pesos intermediários e semelhantes entre si. Apesar do efeito da época de coleta no peso, ela não se refletiu no poder de germinação das sementes. Dentre as sementes aéreas, as grandes germinaram melhor que as pequenas. SAP germinou melhor a 20-35 ${ }^{\circ} \mathrm{C}$ e SAG com e sem envoltório a $25{ }^{\circ} \mathrm{C}$. SAG, com e sem envoltório, apresentou maior porcentagem de germinação e maior IVG quando submetida aos tratamentos de quebra de dormência (CTS ou armazenamento por quatro meses); o CTS e o armazenamento não alteraram significativamente a germinação e o IVG de SAP. O IVG foi maior em sementes aéreas armazenadas por quatro meses e submetidas a $25{ }^{\circ} \mathrm{C}$. Sementes subterrâneas tiveram sua germinação diminuída quando o período de armazenamento aumentou de três para seis meses; o CTS diminuiu a germinação da SSG e aumentou a germinação da SSP. O grau de dormência diferiu muito entre os quatro tipos de sementes. A produção de sementes polimórficas com grandes diferenças no grau de dormência permite que $C$. benghalensis germine e se estabeleça nos mais diversificados ambientes e em diferentes épocas do ano, o que dificulta o manejo desta espécie daninha.

\section{LITERATURA CITADA}

BLACKSHAW, R.E.; STOBBLE, E.H.; SHAYKEWICH, C.F.; WOODBURY, W. Influence of soil temperature and soil moisture on green foxtail (Setaria viridis) establishment in wheat (Triticum aestivum). Weed Science, v.29, p.179-184, 1981.

BRASIL. Ministério da Agricultura e Reforma Agrária. Regras para análise de sementes. Brasília - DF: SNDA/DNDV/CLV, 1992. 375p.

BUDD, G.D.; THOMAS, P.E.L.; ALLISON, J.C.S. Vegetative regeneration, depth of germination and seed dormancy in C. benghalensis L. Rhod. J . Agric. Res., v.17, n.2, p.151-153, 1979.
GONZALEZ, C.B.; HADDAD, C.R.B. Efeito da luz e temperatura na floração e germinação de sementes de Commelina benghalensis L. Arq. Biol. Tecnol., v.38, n.2, p. 651-659, 1995.

HOLM, L.G.; PLUCKNETT, D.L.; PANCHO, J.V.; HERBERGER,J.P. The world's worst weeds distribution and biology. Honolulu: East-West Food Institute, 1977. p. 225-235.

KIM, S.Y. Growth and development of Commelina benghalensis L. from four seed types. Kor. J . Weed Sci., v.18, n.1, p. 42-47, 1998.

KISSMANN, K.G.; GROTH, D. Plantas infestantes e nocivas. Plantas inferiores - monocotiledôneas. São Paulo: BASF Brasileira, 1991-1992. p.96109. T. 1

MAGUIRE, J.D. Speed of germination - aid in selection and evaluation for seedling emergence and vigor. Crop Sci. , v.2, n. 1, p. 176-177, 1962.

MAHESHWARI, P.; MAHESHWARI, J.K. Floral dimorphism in Commelina forskalaei Vahl and C. benghalensis L. Phytomorphology, v.5, n.4, p. 413-422, 1955.

MARTIN, R.J.; CARNAHAN, J.A. The effect of field storage and laboratory conditions on germination of five Xanthium species. Aust. J . Agric. Res., v.34, p. 249-260, 1983.

RODRIGUES, B.N. Estudos sobre a dormência, crescimento, absorção de macronutrientes e resposta à calagem por $\mathbf{C}$. benghalensis $\mathbf{L}$. Jaboticabal: UNESP, 1992. 129p. Tese (Doutorado em Produção Vegetal) - Universidade Estadual de São Paulo, 1992.

WALKER, S.R.; EVENSON, J.P. Biology of Commelina benghalensis L. in South-Eastern Queensland. 1.Growth, development and seed production. Weed Res., v.25, p.239-244, 1985a.

WALKER, S.R.; EVENSON, J.P. Biology of Commelina benghalensis L. in south-eastern Queensland. 2 . Seed dormancy, germination and emergence. Weed Res., v.25, p.245-250. 1985b.

WILSON, A.K. Commelinaceae - A review of the distribution, biology and control of the important weeds belonging to this family. Trop. Pest Maneg., v.27, n.3, p.405- 418, 1981. 